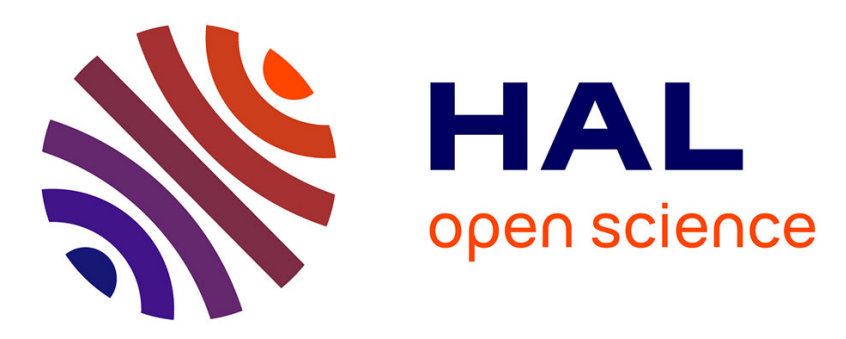

\title{
How far ambient noise measurement may help to assess building vulnerability?
}

Claude Boutin, Stéphane Hans

\section{To cite this version:}

Claude Boutin, Stéphane Hans. How far ambient noise measurement may help to assess building vulnerability?. Increasing Seismic Safety by Combining Engineering Technologies and Seismological Data, Springer Netherlands, pp.151-180, 2009, NATO Science for Peace and Security Series C: Environmental Security. hal-00941256

\section{HAL Id: hal-00941256 https://hal.science/hal-00941256}

Submitted on 3 Feb 2014

HAL is a multi-disciplinary open access archive for the deposit and dissemination of scientific research documents, whether they are published or not. The documents may come from teaching and research institutions in France or abroad, or from public or private research centers.
L'archive ouverte pluridisciplinaire HAL, est destinée au dépôt et à la diffusion de documents scientifiques de niveau recherche, publiés ou non, émanant des établissements d'enseignement et de recherche français ou étrangers, des laboratoires publics ou privés. 


\title{
Chapter 3.1 \\ How Far Ambient Noise Measurement May \\ Help to Assess Building Vulnerability?
}

\author{
Claude Boutin and Stéphane Hans
}

\begin{abstract}
The use of noise data in seismic diagnosis of buildings is analyzed. From the responses to ambient noise, harmonic excitation and shocks, the dynamic behavior of usual buildings is identified in the range of $10^{-5}-10^{-2} \mathrm{~g}$. Taking advantage of the demolition, the influence of the light work elements, full precast facade panels, bearing masonry walls and the presence of neighboring joined buildings is determined. These experiments show that noise measurements efficiently provide reliable data of real interest for understanding the actual building behavior.

Then, the integration of these data in a vulnerability diagnosis is presented. It is shown that regular concrete structures are described by suited beam modeling. Thus for a given structure, taking into account the noise data, the adequate beam model, and taking the maximum tensile and compression strains of concrete and steel as damage criteria, two levels of ground acceleration can be determined, namely the Seismic Thresholds of Elasticity and of Yielding. Quantify the levels that onset the structural damages and the plastic hinge may be a useful tool for vulnerability diagnosis.
\end{abstract}

Keywords Ambient noise - Structural dynamics - Generalized beams for buildings . Vulnerability $\cdot$ Seismic thresholds of integrity and yielding

\subsubsection{Introduction}

The macroseismic intensity scale, based on observed damages after earthquakes, constitutes the first frame of statistical analysis of vulnerability, according to the typology of structures. Introducing qualitative factors known to increase the

C. Boutin $(\otimes)$ and S. Hans

Université de Lyon, Laborataire Géomateriaux, Département Génic Civil et Bâtiment,

URA CNRS 1652

and

Ecole Nationale des Travaux Publics de l'Etat, rue Maurice Audin, 69518 Vaulx-en-Velin, France e-mail: claude.boutin@entpe.fr; stephane.hans@entpe.fr 
vulnerability (transparency, asymmetry) leads to a finer frame of analysis than the solely typology. Such statistical information are relevant at large scale - for instance when assessing the seismic vulnerability of a city (Benedetti et al., 1988; Spence et al., 1992) - despite the large standard deviations reported by every post earthquake survey. In fact, because of the large number of structures, the random errors vanish by summation and the mean value is reached.

The question is more complex when the vulnerability of given structure(s) have to be assessed. Obviously, the statistical information attached to the category of the studied structure is of first importance. However, the knowledge of the category's mean value is not sufficient, because of the possible unknown deviation for this particular building. For instance, a structure belonging to the category " $60 \%$ of chance of moderate damages" can actually be severely or weakly damaged.

To reduce the uncertainty, data specific to the studied structure have to be integrated. However, the number of buildings to be evaluated avoid sophisticated but very time-consuming methods, and argue in favour of procedures as simple and reliable as possible. These obligations introduce two mains questions:

- How to reduce the deficiency of information on a given building by going from qualitative to relevant quantitative information?

- How to exploit efficiently this complementary specific information in terms of vulnerability for the considered building?

This work attempts to answer these two questions. At the light of experiments on real buildings, and on the basis of realistic, tough simple modeling, the aim is to propose a protocol giving practical criteria of interest for a vulnerability diagnosis.

The first part of this chapter focus on the first question by investigating in detail the interest of in situ dynamic monitoring tests (Hudson, 1970) and particularly the ambient noise measurements. This latter auscultation method, that records vibrations at a level much smaller than that induced by seismic events, is frequently criticized. Trough experiments realized with ambient noise, shaker and shocks, on intact and modified buildings (Boutin and Hans, 1998; Boutin et al., 2005; Hans, 2002; Hans et al., 2005), it will be shown that - for practical applications and with sufficient care in the use of the data - the critics are not founded in most cases.

The Section 3.1.2 is devoted to the experimental procedure and data processing. The Section 3.1.3 focus on the identification of the behavior of usual buildings built according to the design rules of common practice - from a weak level of acceleration (ambient noise $\approx 10^{-5} \mathrm{~g}$ ) to a medium level (shock $\approx 10^{-2} \mathrm{~g}$ ), with and without soil structure interaction. The modal characteristics gathered during progressive demolitions are exposed in Section 3.1.4 and show:

- A significant influence of full precast facade panels and bearing masonry walls

- The weak influence the light work elements like secondary dividing walls,...

- The weak influence of the presence of neighboring joined buildings

Section 3.1.5 synthesises the main lessons drawn from this experimental program. 
The second part is dedicated to the second point, i.e., the links between the experimental data and a draft diagnosis. This purpose is achieved in two steps:

- First - in the framework of generalized beam theory describing the behaviour of regular buildings - the identification of criteria enabling to relate the modal characteristics extracted from the measurements to the mechanical functioning of the structure (Section 3.1.6)

- Second, the definition and calculation of the so called Seismic Thresholds of Elasticity and Yielding suited to a given structure (Section 3.1.7)

This procedure highlights the actual interest of coupling both experimental data and relevant beam modelling of the building for establishing a vulnerability diagnosis.

\subsubsection{Monitoring methods and tested structures}

\subsubsection{In situ monitoring methods}

Testing real structures enable identifying some phenomena otherwise difficult to reproduce or identify in idealized laboratory experiments. In addition, these experiments avoid the sensitive questions of the scale similarities which interfere with the interpretation of tests at reduced scale or enlarged time. In counter part, the tested structures are only partially known and the range of loading is limited.

The in situ testing method consisted in recording the accelerometer responses of the structure. Three types of excitations were used to identify frequencies, modal shapes and non-dimensional damping ratios: ambient loads, harmonic excitation (using a mechanical shaker constituted by two counter-rotating masses) and shock loading (induced by a mechanical shovel). Whatever the excitation is, the acceleration is small enough not to move the structure's response beyond its elastic domain.

The measurement device is composed of:

- Twelve ICP 1D accelerometers of sensibility of $10^{-5} \mathrm{~g}$, linear in the range $0-80 \mathrm{~Hz}$

- A 12-channel HP3566A synchronized analogical recorder

- A PC with HP software driving the hardware storage and the signal processing

A sampling frequency of $128 \mathrm{~Hz}$ and a time-recording of $64 \mathrm{~s}$ were retained to avoid problems of spectrum folding and cut-off frequency, permitting to analyze a $0-50 \mathrm{~Hz}$ frequency bandwidth sufficient to capture the modes of interest in the seismic range. The accelerometers were located in the center of the structural cross-section, one at the first floor, one at the top floor, the others in the intermediate levels. Longitudinal (lengthwise) or transverse (in the direction of the width) oscillations may be recorded independently when changing the accelerometers orientation. In this study, the attention is focused on horizontal vibrations, more critical for the seismic risk than vertical vibrations. 


\section{Ambient vibrations}

This method, initiated in the 1970s, (Stubbs and MacLamore, 1973; Trifunac, 1972), knows actually large developments due to its simplicity, (Farsi, 1996; Ivanovic et al., 2000). Ambient vibrations result from a mechanical noise (earth and urban activity) transmitted to the structure through the soil. Wind and internal activity could also contribute, however, in this study, the measurements were made by calm weather in buildings free of inhabitants. It has been verified that on the ground the density of probability of the signals is Gaussian, enabling to consider that the building responds to a white noise imposed motion. The horizontal acceleration is of the order of $10^{-5} \mathrm{~g}$ at the bottom and $10^{-4} \mathrm{~g}$ at the top.

\section{Harmonic forcing}

Harmonic oscillator was used for instance by Englekisk and Matthiesen (1967), Jennings and Kuroiwa (1968) or Petrovski et al. (1973) as device to identify the dynamic behavior of structures. Here a shaker (CEBTP) constituted by two counterrotative masses was used. This device delivers in a given horizontal direction a sinusoidal horizontal force controlled in amplitude (maximum 7,000 N) and frequency (in the range 1-10 Hz), (Paquet, 1976).

Tests consist in fixing the oscillator at the center of the top floor with two orientations corresponding to the main directions of the building. Accelerations are recorded in harmonic steady state regime and in free oscillation regime (after the shaker is switched off). The horizontal accelerations reaches $10^{-4} \mathrm{~g}$ at the basis and $10^{-3} \mathrm{~g}$ at the top, i.e. about ten times the level induced by the ambient vibrations.

\section{Shocks}

Shocks tests were realized by impacting the building in the two main directions (generally at an high storey and at the center of the facade) by means of an heavy mechanical shovel (usually used for demolition). It should be mentioned that the damage (when it appears) is localized in the very vicinity of the impact and outside this zone the structure remains entirely intact. The accelerometers triggered before the shock records the entire free oscillations response.

Compared to ambient vibrations and harmonic oscillations, the short impulsive record is of larger magnitude, giving a pick acceleration of about $10^{-2} \mathrm{~g}$ even on the ground floor, i.e. 1,000 times greater than the ambient level.

\subsubsection{Tested structures}

The tested building - located in Vaulx-en-Velin, suburbs of Lyon, France - were all in good condition, their demolition was subsequent to an new urban designed 
planning policy. They are representative, from both engineering and architectural points of view, of number of urban buildings erected between 1970 and 1975. Some common characteristics are:

- Structural regularity in plan (with transverse and longitudinal symmetry)

- Structural regularity in elevation (all levels identical, no transparency on the ground floor)

- Weak amount of steel reinforcement bars in the concrete elements (of standard thickness of $15 \mathrm{~cm}$ ) and very poor steel reinforcement in the precast panels

The soil is mixed gravel and consolidated clay deposits with good mechanical properties; a surface wave measurement indicates a shear wave velocity around $300 \mathrm{~m} / \mathrm{s}$ at $5 \mathrm{~m}$ depth. All the tested buildings are founded on shallow foundations.

\section{Features of buildings}

The cross-sectional plans of typical floor and a picture of the tested structures are presented in the Figure 3.1.1. Their main characteristics are described below:

- Building $\mathrm{C}$ of eight storeys was constructed using the industrial "tunnel casing" technique; the floors and transverse shear walls are made by reinforced concrete; the lengthwise bracing is mainly provided by the two full precast facade panels and the shaft walls of the lift.

- Buildings D, E, F, of five storeys, have floors of reinforced concrete associated, external shear bearing walls in light parpen (masonry bricks) and internal shear bearing walls in heavy parpen (bricks); they were roughly placed on an axe parallel to one of their diagonal and separated by $5 \mathrm{~cm}$ gaps filled with polystyrene that run only over a small part of the longitudinal facade.
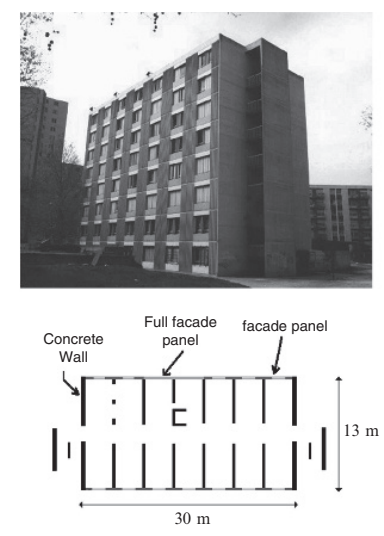
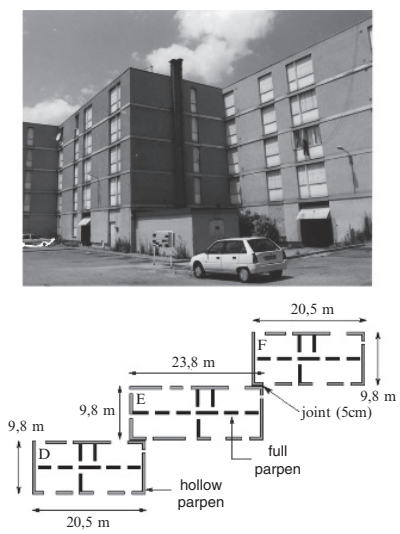

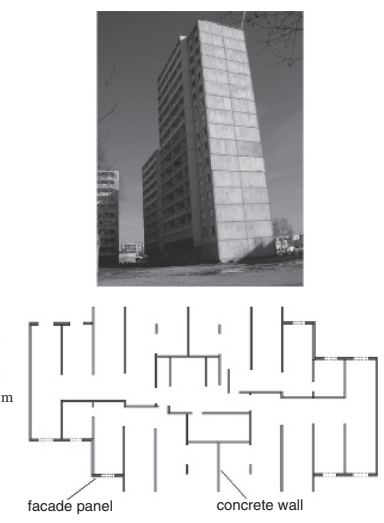

Fig. 3.1.1 The tested buildings and their typical floor plan view 
Table 3.1.1 Dimensions and masses of tested buildings

\begin{tabular}{lccccc}
\hline Building & C & D & E & F & G \\
\hline Length $\mathrm{L}(\mathrm{m})$ & 30.0 & 20.5 & 23.8 & 20.5 & 31.4 \\
Width W $(\mathrm{m})$ & 14.0 & 9.8 & 9.8 & 9.8 & 13.4 \\
Height H (m) & 21.6 & 14.1 & 14.1 & 14.1 & 43.2 \\
H/W ratio & 1.54 & 1.45 & 1.45 & 1.45 & 3.22 \\
H/L ratio & 0.72 & 0.69 & 0.59 & 0.69 & 1.38 \\
L/W ratio & 2.14 & 2.1 & 2.44 & 2.1 & 2.33 \\
Story specific mass $\left(\mathrm{t} / \mathrm{m}^{3}\right)$ & 0.27 & 0.23 & 0.23 & 0.23 & 0.25 \\
Linear mass $(\mathrm{t} / \mathrm{m})$ & 114 & 46 & 53 & 46 & 110 \\
\hline
\end{tabular}

- Building G of 16 storeys presents floors and longitudinal and transversal shear walls in reinforced concrete; the facades are made by precast panels.; close to this building, separated by a $5 \mathrm{~cm}$ gap, a similar building of 11 storeys is located.

Table 3.1.1 shows the dimensions and slender parameters of these buildings, together with their storey density and lineic mass, both deduced from the plans and the usual density value of materials.

\subsubsection{Analysis of the records}

The classical framework of modal analysis is used to extract information from the records. This is well supported by the experimental facts among them:

- The presence of sharp peaks in the response spectra which indicates a notable response amplification at those frequencies.

- The fact that those frequencies are identical in any point of the structure which proves that, actually, the whole structure is affected by the same oscillation.

- The good agreement of the results derived from multi-type loadings (random, harmonic, shock) and very different levels of amplitudes (ranging over four decades) which illustrates the characteristic feature of (quasi-)linear systems.

- Systematically, the $n$th modal shape has $n$ fix nodes.

Theoretically, all the modes appear simultaneously in the response. Nevertheless as the eigenfrequencies of studied buildings were well separated and the damping weak (see Table 3.1.2), the contribution of the other modes at the frequency of a given mode can reasonably be neglected, at least for the few first modes.

\section{Processing technics}

The signals are processed either in spectral or in time domain.

Spectra of ambient vibrations (with smoothing), free oscillations and shocks have been calculated by Fast Fourier Transform (FFT). The modal frequencies and shapes 
Table 3.1.2 Modal characteristics of buildings C and G

\begin{tabular}{|c|c|c|c|c|c|c|c|}
\hline \multirow{3}{*}{$\begin{array}{l}\text { Building } \\
\text { Direction } \\
\text { Mode number }\end{array}$} & \multirow[b]{3}{*}{$\begin{array}{l}\text { Monitoring } \\
\text { method }\end{array}$} & \multirow{2}{*}{\multicolumn{2}{|c|}{$\begin{array}{c}\text { Building C } \\
\text { Longitudinal }\end{array}$}} & \multicolumn{4}{|c|}{ Building $\mathrm{G}$} \\
\hline & & & & \multicolumn{2}{|c|}{ Longitudinal } & \multicolumn{2}{|c|}{ Transversal } \\
\hline & & $\begin{array}{l}\text { Freq } \\
(\mathrm{Hz})\end{array}$ & $\zeta(\%)$ & $\begin{array}{l}\text { Freq } \\
(\mathrm{Hz})\end{array}$ & $\zeta \mathrm{g}(\%)$ & $\begin{array}{l}\text { Freq } \\
(\mathrm{Hz})\end{array}$ & $\zeta(\%)$ \\
\hline \multirow[t]{4}{*}{ Mode 1} & Ambient & 4.3 & 2.85 & 2.08 & 2.5 & 1.56 & 1.3 \\
\hline & Free osc. & 4.25 & 2.4 & 1.96 & 2.6 & 1.49 & 1.5 \\
\hline & Harmonic & 4.19 & 2.6 & 1.94 & 2.3 & 1.48 & 1.5 \\
\hline & Shock & 4.18 & 4 & - & - & - & - \\
\hline \multirow[t]{4}{*}{ Mode 2} & Ambient & 13.4 & 3.5 & 7 & 2.5 & 6.6 & 4 \\
\hline & Free osc. & - & - & 6.75 & 2.6 & 6.26 & 2.2 \\
\hline & Harmonic & - & - & 6.73 & 2.4 & 6.17 & 2.3 \\
\hline & Shock & 12.8 & 4 & - & - & - & - \\
\hline \multirow[t]{2}{*}{ Mode 3} & Ambient & 23 & 4 & 12.8 & 12 & 13.5 & 5 \\
\hline & Shock & 22.5 & 3.8 & - & - & - & - \\
\hline Mode 4 & Ambient & - & - & 20 & 4 & - & - \\
\hline
\end{tabular}

of the coupled soil-structure system are simply deduced by peak-picking. The damping ratio is assessed from the pass-band width. A similar procedure applies for the calculation of the modal transfer functions of the structure on fixed base (see below).

The process in the time domain are specific for each kind of signal. Random signals are firstly filtered around each modal frequency, then the autocorrelation functions are determined. From these, the mode shape is deduced by extracting the extrema and the modal damping ratio is derived very accurately from the logarithmic decrement. Harmonic responses are exploited classically. Eigenfrequencies are identified from the maximum sweep response, mode shapes from the amplitudes at the eigenfrequencies and damping ratio from the sweep response bandwidth. Finally some impulse responses under shocks were processed using Cauchy wavelet (Argoul et al., 2000). The amplitude patterns of the wavelet transforms enable a refined determination of the modal characteristics and even reveal the weak nonlinearity effects when occur.

\section{Structure-soil system and structure on fixed basement}

The in-situ measurements naturally lead to the modal characteristics of the structure coupled with the soil. However, when the soil presents good characteristics, as in the present case, a weak contribution of the soil-structure interaction might be expected and therefore, the modal parameters of the structure coupled with the soil (SS) to be close to those of the structure lying on a rigid basis (SB), at least for the first modes. When possible, it is interesting to derive the own modal characteristics of the structure on fixed base, corresponding to the intrinsic properties of the structure.

Assuming that the building base is infinitely rigid, the soil-structure system is composed of two coupled sub-systems, (i) the soil, and (ii) the structure on rigid 
basement (SB). In the case of ambient vibrations due to soil motions, a weak soil-structure interaction means that the base motion is almost identical to the incident motion. Thus, it can be considered that the structure motions, observed in the non-galilean frame attached to the base, define the SB transfer functions. Consequently the intrinsic behavior of SB structure is deduced by suppressing the rigid body motion induced by the base motion.

Conversely, for shaker excitation and shocks, since the level of vibration is much higher than the level of the ambient soil motion, it is expected that the base motion be mainly due to the soil-structure interaction; therefore, the identification of the SB behavior from the SS behavior would require more sophisticated derivations.

\subsubsection{Results concerning intact structures}

\subsubsection{Identification of modal characteristics}

Modal frequencies and damping ratio for buildings $\mathrm{C}$ et $\mathrm{G}$ are gathered in Table 3.1.2 and the corresponding modal shapes are presented in Figures 3.1.2 and 3.1.3. A very good agreement is observed between the results given by different vibration methods. This result was systematically observed for all the tested buildings.

These experimental findings confirm that from small amplitudes of ambient vibrations to significantly larger amplitudes (shocks), the structures respond systematically by following the same quasi-elastic behavior (Trifunac, 1972). An important conclusion is that ambient measurements are sufficient to identify the structure's behavior for the whole quasi-elastic domain.

Mode 1 L

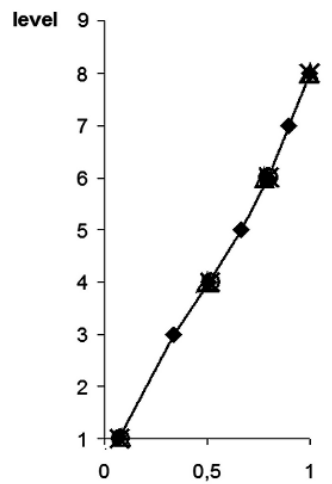

Mode 2 L

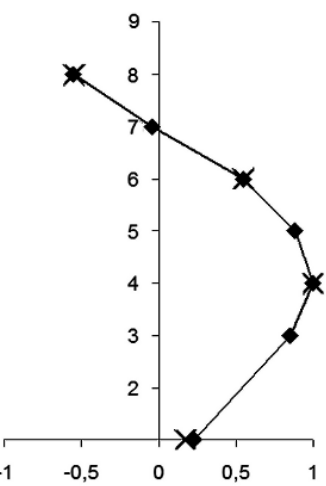

Mode 3 L

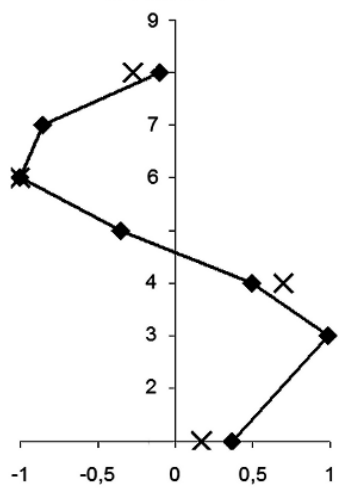

$\longrightarrow$ ambient $\rightarrow$ harmonic $\triangle$ free oscillations $\rightarrow \leftarrow$ shock

Fig. 3.1.2 Mode shapes of building $\mathrm{C}$ in longitudinal direction identified from the several types of excitation 


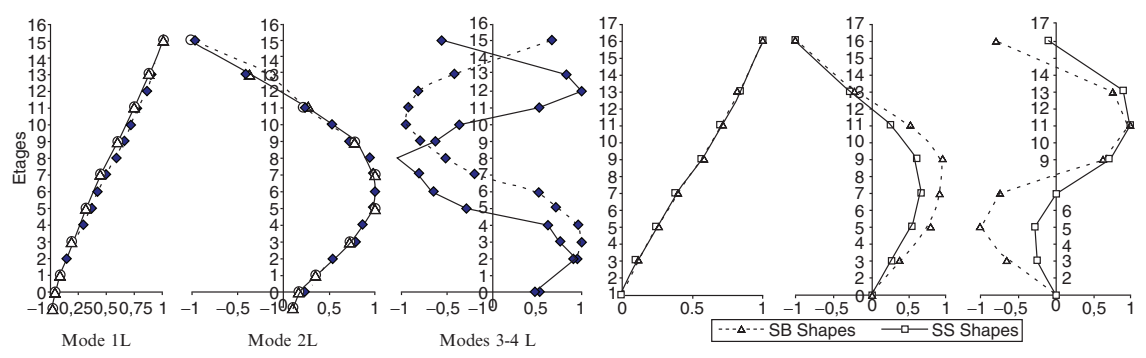

Fig. 3.1.3 Modal shapes of building G. Left, modal shapes of the system soil-structure (SS). Right, comparison between SB modal shapes (obtained by extracting the soil-structure interaction) and SS modal shapes (whose base motions were nullified)
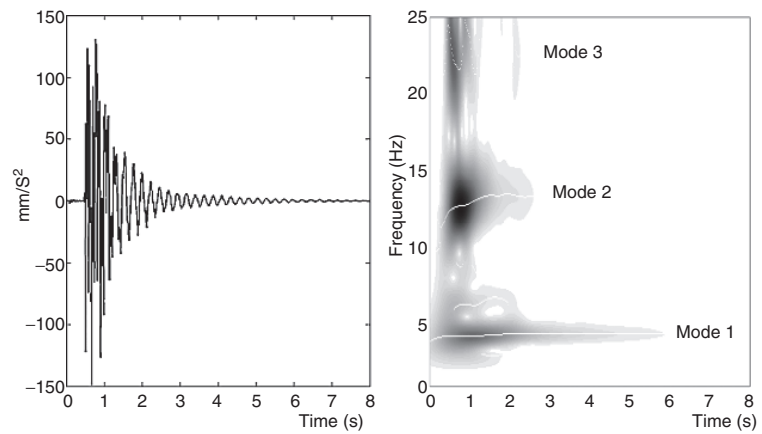

Fig. 3.1.4 Shock on building C (longitudinal direction). Left, temporal record. Right, wavelet analysis. Note the presence of three modes and the slight migration of eigenfrequencies corresponding to a weak non-linear effect when amplitude varies from $10^{-2}$ to $10^{-5} \mathrm{~g}$

\subsubsection{Weak non-linear effects}

The tests bring to the fore a weak non-linearity of the buildings, function of the motion amplitude. Systematically, the eigenfrequencies tends to decrease from ambient to shocks tests (Table 3.1.2). Nevertheless, this fall is of order of 2-5\% while amplitude wins a factor 1,000 (from about $10^{-5}$ to $10^{-2} \mathrm{~g}$ ). The variations on damping are not so clear and any modification of modal shapes seems occur. This phenomena has already been observed in the past by different authors (e.g. Ellis (1996), Jennings and Kuroiwa (1968)).

To investigate this non-linear effect, a wavelet analysis has been realized on shocks tests. This provides the instantaneous characteristics of a transient signal, i.e., in function of the time, the modal frequencies and modal amplitudes from which the associated damping or shapes can be deduced. As a shock response ranges from high level at the beginning to ambient level at the end, a good overview can be obtained (Figure 3.1.4). In time-frequency domain, the first three vibration modes (respectively between 4.1 and $4.3 \mathrm{~Hz}, 12.8$ and $13.5 \mathrm{~Hz}$ and around $22.5 \mathrm{~Hz}$ ) appear with a clear temporal localization, the third mode being quickly damped, followed by the 
second and finally the first. This analysis shows a light decrease of the eigenfrequencies and a light increase of the modal damping with the increase of amplitude response. This softening behavior is very similar to soil behavior. It seems hence reasonable to localize the origin of this non-linearity in the soil foundation through soil-structure interaction phenomena. It has nevertheless to be underlined that the modal shapes do not present any variation. The observed variations are sufficiently limited (never more than 7\%) to be neglected in first approximation in case of good soils.

\subsubsection{Soil-structure interaction}

The modal shapes of building G, presented on Figure 3.1.3, are related to the real system (SS) - that includes the soil participation in the dynamics - and the structures on fixed base (SB) (cf. "Structure-soil system and structure on fixed basement"). Clearly a (SS) displacement of the base is visible, increasing from the first to the higher modes. According to the procedure given in the section "Structuresoil system and structure on fixed basement", the characteristics of the structures on fixed base (SB) are deduced and compared in Table 3.1.3 and Figure 3.1.3 with SS modal characteristics. As expected, the SS eigenfrequencies are smaller than SB ones, because of the softness induced by the soil. Moreover, the differences grow for higher modes. This is consistent with the increase of the modal stiffness of the structure with modal number, leading in turn to increase the soil-structure interaction:

- For the first and second modes, the modal stiffness is too low to initiate significant interaction with the soil, and, de facto, there is small differences between SB and SS modal characteristics.

- For higher modes, the modal structure stiffness grow quickly and larger modification of the modal characteristics appears.

It is worth to mention that, for studied buildings, this effect is limited (less than $5 \%$ for the eigenfrequencies), so that, for a seismic vulnerability point of view, soilstructure interaction does not modify significantly the seismic behavior.

Table 3.1.3 Soil-structure interaction - comparison between soil-structure (SS) and structure-onfixed-base modal frequencies (SB) for buildings $\mathrm{C}$ and $\mathrm{G}$

\begin{tabular}{lccccc}
\hline Building & \multicolumn{2}{c}{ Building C } & \multicolumn{2}{c}{ Building G } \\
\hline Direction & Mode & SS (Hz) & SB (Hz) & SS (Hz) & SB (Hz) \\
\hline Longitudinal & 1 & 4.32 & 4.45 & 2.08 & 2.15 \\
& 2 & 13.5 & 14.1 & 7 & 7.25 \\
Transversal & 3 & 23 & 23.6 & 12.8 & 14 \\
& 1 & 4.5 & 4.66 & 1.56 & 1.56 \\
& 2 & - & - & 6.6 & 6.65 \\
& 3 & - & - & 13.5 & 14 \\
\hline
\end{tabular}




\subsubsection{Experiments on modified buildings}

Measurements on real buildings may be actually of interest for seismic assessment, provided that they represent the effective dynamic behavior before significant structural damages. This question is nevertheless difficult to address theoretically because of the lack of reliable information for modelling parasite phenomena that may modify the modal characteristics. Thus experiments dedicated to the analysis of these perturbation effects (presence of light work elements,...) provide qualitative, or when possible, quantitative estimates. In this aim, tests were also performed after modifying the buildings or their immediate vicinity. If general conclusions can not be drawn from the particular studied cases, the trends will nevertheless be useful for number of buildings presenting similar configurations.

\subsubsection{Effect of light work elements}

How large extent can the presence of light work elements influence the modal characteristics? The additional mass of these elements can reasonably be estimated to about 5\% (or less) of the mass of the structure. The difficulty lies in the additional stiffness brought by the light elements well connected to the structure. A direct quantification is unrealistic because of the large number of unknowns.

The demolition of the building $\mathrm{G}$ gave the possibility to investigate on this aspect. As the concrete was intended to be recycled after demolition, any contamination with the other construction materials was avoid. For this reason, the light elements as the secondary dividing walls in plaster or bricks (thickness of 5-7 cm), the windows and their aluminium frames, the doors and doorways in wood and steel, were taken off before beginning the demolition of the 'naked' concrete structure.

Ambient vibrations measurements were performed on the cleared structure. The comparison with the spectra of the intact building is given in Figure 3.1.5. It appears that removing the whole non structural elements induces a slight (but clearly measurable) decrease of eigenfrequencies of about 3-4\%. This means that, in the considered case, the stiffness effect is more significant than the mass effect.

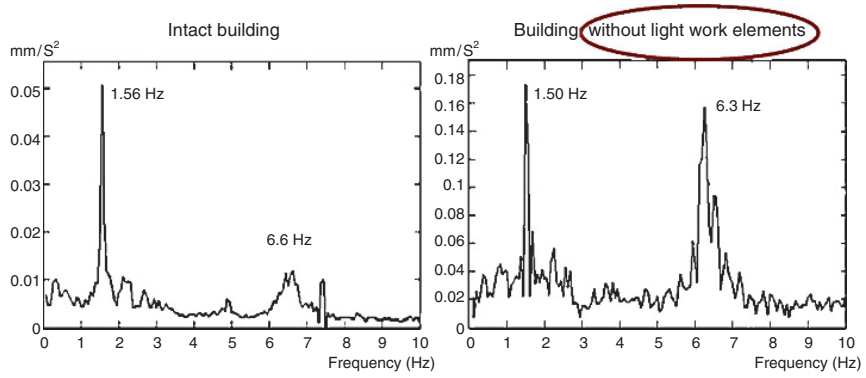

Fig. 3.1.5 Examples of Fourier transforms of ambient vibrations measurements realized on building $\mathrm{G}$ before and after the removal of light work elements (transverse direction) 
It can be also deduced that, for this kind of very common buildings equipments, the presence of these non-structural elements increases the shear and bending stiffness by about $6-8 \%$. This effect can therefore be neglected in a first analysis.

\subsubsection{Importance of masonry parpen walls}

The role of the masonry parpen wall in the modal behavior is not always clear, essentially because the material properties are not very well known, and the quality of the connections with the other structural elements is questionable.

In building $\mathrm{F}$, the influence of walls made of light parpen was investigated in the following way. The entire wall (i.e. for the four storeys) constituting the south facade was demolished, leaving unmodified the rest of the building (Figure 3.1.6). Then free oscillations after impacts in the North-South and East-West directions were recorded. Note that the destruction of the wall broke the quasi-symmetry of the intact building, so that a pure E-W translation mode is no more possible. The Figure 3.1.6 shows the comparison of the responses spectra for the intact and modified building.

In the E-W direction (shear direction of the destroyed wall), a drastic reduction of the eigenfrequency from 5.15 to $4.5 \mathrm{~Hz}$ is observed. This leads to a roughly assessment of the wall contribution about a quarter of the storey stiffness. This estimate is consistent with the reduction of the total length of the E-W shear walls.

In the N-S direction (out of plane bending of the destroyed wall), the frequency of the main peak remains the same, meaning that the out of plane stiffness is negligible in regard to the shear stiffness of the N-S walls (the secondary peak at the same frequency $[4.5 \mathrm{~Hz}]$ than in the E-W direction may result either from the coupling between both directions or from an imperfect direction of the impact).
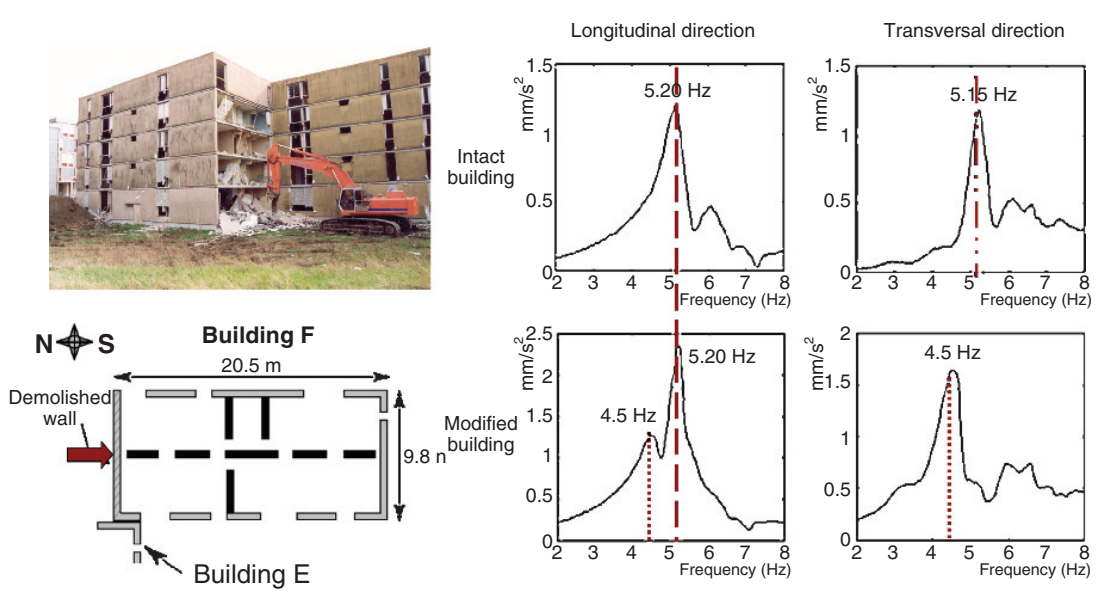

Fig. 3.1.6 Modification of building F - the wall has been demolished from the base to the top of the building and comparison of the spectrum responses for the intact and modified building 
Additionally, those experiment enables, from a simple discrete shear beam model, to assess the equivalent modulus of the heavy and light parpen respectively to $E_{F P} \approx 2.7 \mathrm{GPa}$ and $E_{H P} \approx 1.5 \mathrm{GPa}$. These values, which are ten times smaller than for a concrete, are consistent with those given in the literature.

To conclude, despite the presence of internal walls of heavy parpen, the contribution of the light parpen walls (in their shear direction) is very significant and cannot be neglected. This result is of first importance for framed building with masonry infill. This conclusion is supported by number of post earthquake reports, mentioning that the absence of infills at the ground level creates a critical 'transparent' storey.

\subsubsection{Role of plain precast facade panels}

Precast facade panels are widely used in recent buildings. It is generally assumed that their connection with the concrete structure is sufficiently good to consider that the full panels (i.e. without large opening for windows) may participate to the horizontal strength of the building. This point was checked by means of a step by step demolition realized on the building $\mathrm{C}$ which included two full panels by storey. At first, at the ground level, a panel of the longitudinal North-West facade was removed. Then a shock were applied in the N-W direction (shear direction of the removed panel) and the free oscillations recorded. The same procedure were reproduced twice for the two plain panels at the second level.

The spectra recorded in the four states (intact and 1,2,3 removed panels) are presented in Figure 3.1.7 where a zoom around the first longitudinal eigenfrequency is plotted. A slight but measurable regular decrease of the frequency clearly appears, although the modifications only affect two of the eight storeys. By a simple

Facade

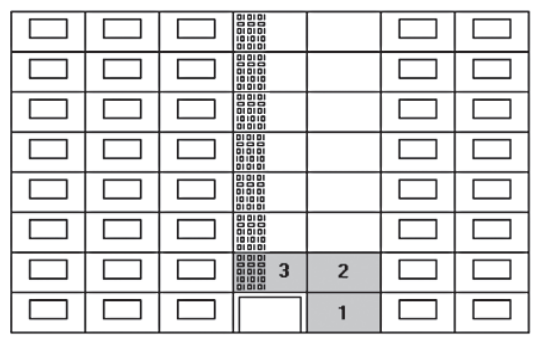

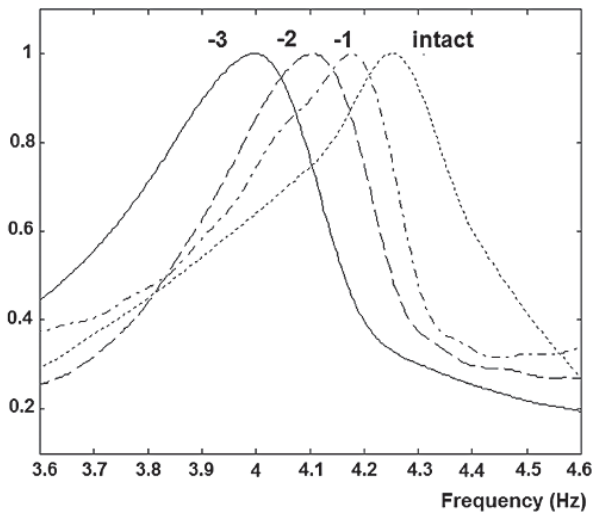

Fig. 3.1.7 Evolution of first longitudinal eigenfrequency during the successive removals of full precast panels on the building $\mathrm{C}$ 
modelling based on discrete shear beam, one deduces that the contribution of the two panels to the storey shear stiffness lies in between $20 \%$ and $25 \%$.

This confirms that full panels in their shear direction can not be neglected for interpreting the modal behavior. Let us mention that, as the parpen walls, the panels are almost unreinforced and would not present any ductility.

\subsubsection{Influence of neighboring joined buildings}

The possible mutual influences of close building are generally disregarded. This point was investigated in the group of the three similar buildings D, E, F: the ambient vibrations of the intact building $\mathrm{D}$ was recorded in presence of buildings $\mathrm{F}$ and $\mathrm{E}$, then again after demolishing F, and finally after both $\mathrm{F}$ and $\mathrm{E}$ were destroyed.

The resulting modifications of the first eigenfrequency are given in Table 3.1.4. In both directions, the successive demolitions induced a systematic decreasing of the frequencies. The differences are not negligible and can reach $10 \%$ in the more significant case. As the ambient motion is very small compared to the thickness of the structural joints (which concerns only a small part of the facade), this latter do not play any role in the dynamics. Thus, the origin of the buildings coupling has to be found in the transmission of motions and stresses throughout the soil.

Modeling this dynamic structure-soil-structure interaction would require numerical approaches. Nevertheless an explanation consistent with the measurements can be proposed. Consider two identical joined buildings. The soil stiffness imposes the differential motion of their rigid foundation to be negligible. Therefore both buildings should respond almost as if they were lying on an unique common foundation. Comparing with the same single isolated building, the only difference lies in the fact that, proportionally, the rocking impedance is smaller. Consequently, the eigenfrequency of single building should be smaller than that of the two joined buildings.

This experiment tends to show that the mutual influence, namely the structuresoil-structure interaction, may play a role, especially for close buildings presenting almost the same features (and eigenfrequency). Further experimentations should be carried on before generalizing this conclusion.

Table 3.1.4 Structure-soil-structure interaction - decreasing of fundamental frequency of building $\mathrm{D}$ during the demolition of neighboring buildings $\mathrm{E}$ and $\mathrm{F}$

\begin{tabular}{lcccc}
\hline Building(s) in presence & $\begin{array}{c}\text { D-E-F } \\
\text { intact }\end{array}$ & $\begin{array}{c}\text { D-E intact F } \\
\text { demolished }\end{array}$ & $\begin{array}{c}\text { D intact E-F } \\
\text { demolished }\end{array}$ & $\begin{array}{c}\text { Total } \\
\text { decreasing }\end{array}$ \\
\hline $\begin{array}{l}\text { Longitudinal first frequency } \\
\text { of D (Hz) }\end{array}$ & 5.6 & 5.4 & 5.08 & $9 \%$ \\
$\begin{array}{l}\text { Transversal first frequency } \\
\text { of D (Hz) }\end{array}$ & 5.65 & 5.47 & 5.35 & $5 \%$ \\
\hline
\end{tabular}




\subsubsection{Synthesis of lessons drawn from experiments}

The main lessons drawn from these experiments are that (i) the lack of information on existing buildings may be overcomed by means of ambient vibration measurements, and (ii) that these later do provide data directly linked with the key elements actually participating to the structural behavior.

The very good agreement observed on real buildings when using ambient, harmonic and shock excitation deserve to be emphasized for two main reasons. First, the stability and the consistency of the results prove the robustness and the reliability of information collected through those methods. Second, it demonstrates that almost the same quasi-elastic behaviour remains valid on a wide range of acceleration levels covering the ambient level (around $10^{-5} \mathrm{~g}$ ) up to the shock level $\left(10^{-2} \mathrm{~g}\right.$ for the tested buildings). It is worth mentioning that this result has been somehow extended to earthquakes by Dunand (2005) who performed ambient tests on instrumented Californian buildings. The records of both strong motions and ambient noise show that when buildings suffer a weak level of damage, the shift of eigen frequency is temporary and no more than $20 \%$. Moreover, the top motion in the building under earthquake can be fairly well reproduced from the first mode identification - deduced from ambient noise - and the strong motion recorded on the basis.

The tests performed on intact and modified structures enables to identify and quantify the leading and negligible phenomena that may influence the actual quasielastic behaviour. It is shown that:

- Full precast facade panels or masonry shear walls do have a significant role, and consequently they have to be considered in the analysis of the building behavior.

- On the contrary, the influence of light work elements or the effect of neighbouring structure may exist as perturbation that can neglected in a first approximation.

As these effects are weakly documented, their quantification in some particular cases should be useful in a number of similar situations. Moreover, these investigations point out the elements of the structure that have actually to be considered in the building behaviour before significant damage. This is a key point before to intend integrating in situ data in a diagnosis procedure.

Now, the question is to establish a link between the experimental data and a draft diagnosis. The idea is to exploit the fact that the quasi-elastic behavior:

- Is well defined by ambient noise vibrations

- Coincides with that of the real structure during earthquakes until the onset of structural damages in the concrete

- Might be extended up to the onset of yielding of concrete in compression and of steel bars (in first approximation)

Thus provided that criteria for the onset of tension cracks in concrete and of yielding of steel bars and of concrete in compression are given, two thresholds of damage can be derived from the quasi-elastic vibration modes. This purpose is achieved in two steps. 
The first step consists in relating the modal characteristics extracted from the measurements to the mechanical functioning of the structure. This is developed in Section 3.1.6, in the frame work of the generalized beam theory. In the second step, Section 3.1.7, these results are used to deduce the internal strains associated to the modal deformations. Thus, using as damage criteria for the key structural elements, the strains that onset, (i) cracks in tension within concrete, and (ii) yielding of concrete in compression and of steel bars, the Seismic Thresholds of Elasticity (STE) and of Yielding (STY), suited to a given structure, are derived. These normalized acceleration amplitudes (according to the seismic codes) are directly related to the onset of structural damages and plastic hinges.

This approach is illustrated on the building $\mathrm{C}$. This study case shows how the STE value and the gap between the STE and the acceleration level required by the codes could be of interest for diagnosis of vulnerability.

\subsubsection{Relevant beam model for regular buildings}

It was established that ambient vibration measurements give the modal characteristics of a building with a good reliability in the whole quasi-elastic domain (despite the presence of slight perturbations induced by a few 'parasite' effects). Moreover experiments on modified buildings indicate that this data are directly linked with the response of the key structural elements. But the link between the modal deformation at the global building scale and the internal strain at the structural element scale, where the damages may occur, is not explicitly given by the experimental data.

The aim of this section is to fill this gap by determining relevant though simple beam modelling whose the conformity with the data could by easily checked. In addition, a clear mechanical understanding at both global and local scales, is given by these beam models that condense in a very synthetic way the essential parameters of the dynamic behavior.

\subsubsection{The framework of generalized beams}

The analysis is here focused on regular buildings of height $H$ made of a sufficient number $N$ of identical storey of height $\ell(H=N \ell)$. The building material is assumed to be elastic of Young's modulus $E$. Provided that the scale ratio $\varepsilon=\frac{\pi}{2} \frac{\ell}{H}=\frac{\pi}{2 N}$ is sufficiently small (say $N>5$ ), the homogenization method of discrete structures can be applied to derive the equivalent beam modeling. The theoretical developments, exposed in Boutin and Hans (2003) and Hans and Boutin (2008), show that the dynamic behavior is that of generalized beams controlled by a combination of three mechanisms, namely a shear storey deformation, a global storey bending and an inner storey bending. These mechanisms, illustrated in the Figure 3.1.8, are related to three elastic parameters - the shear stiffness $(K)$, the global bending stiffness $(E I)$ 


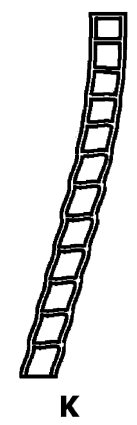

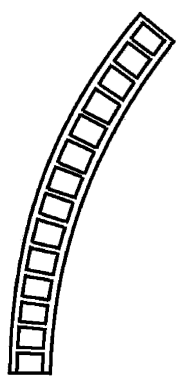

E I

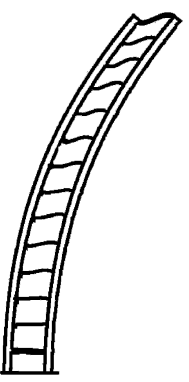

$\mathbf{E I}_{\mu}$

Fig. 3.1.8 Illustration of the three mechanisms driving the transverse dynamic behaviour of periodic hollow structures as buildings

and the inner bending stiffness $\left(E I_{\mu}\right)$ - which are derived from elastic properties of the generic storey under static shear or bending deformations. In the general case where all mechanisms are of the same order, the behaviour is described by the nonclassical beam equation of the sixth degree:

$$
\frac{E I_{\mu} E I}{K} U^{(6)}-\left(E I_{\mu}+E I\right) U^{(4)}-\frac{E I}{K} \Lambda \omega^{2} U^{(2)}+\Lambda \omega^{2} U=0
$$

where $U(x)$ is the horizontal displacement of the floors of the structure. When one mechanisms becomes negligible compared to the others, the general model degenerates into more simple behaviours, namely a slender Timoshenko beam (characterized by $E I$ and $K)$ - Stephen (1999) - or an inner bending-shear beam $\left(E I_{\mu}\right.$ and $K)$ and when only one mechanism is predominant, a pure shear beam $(K)$, a global bending beam $(E I)$ or an inner bending beam $\left(E I_{\mu}\right)$ is obtained.

Two dimensionless parameters are introduced to estimate the weight of each mechanism relatively to the others, namely:

$$
C=\frac{E I}{K L^{2}} \quad \gamma=\frac{E I_{\mu}}{E I}
$$

where $L=2 H / \pi$. The parameter $C$ evaluates the global bending effect compared to the shear effect and $\gamma$ the inner bending effect compared to the global bending effect. The change of variable $\mathrm{x}=x / L$ and $\omega^{* 2}=\Lambda \omega^{2} L^{2} / K$ transforms Equation (3.1.1) to its dimensionless form:

$$
C \gamma U^{*(6)}-(1+\gamma) U^{*(4)}-\omega^{* 2} U^{*(2)}+\frac{\omega^{* 2}}{C} U^{*}=0
$$

By comparing the values of $C, \gamma$ and $C \gamma$ with powers of $\varepsilon$, i.e. writing:

$$
C=\varepsilon^{\alpha} \quad \gamma=\varepsilon^{\beta} \quad \varepsilon=\frac{\pi}{2 N}
$$

seven possible behaviours are identified according the value of $\alpha$ and $\beta$. The domain of validity of each model is represented on Figure 3.1.9. 


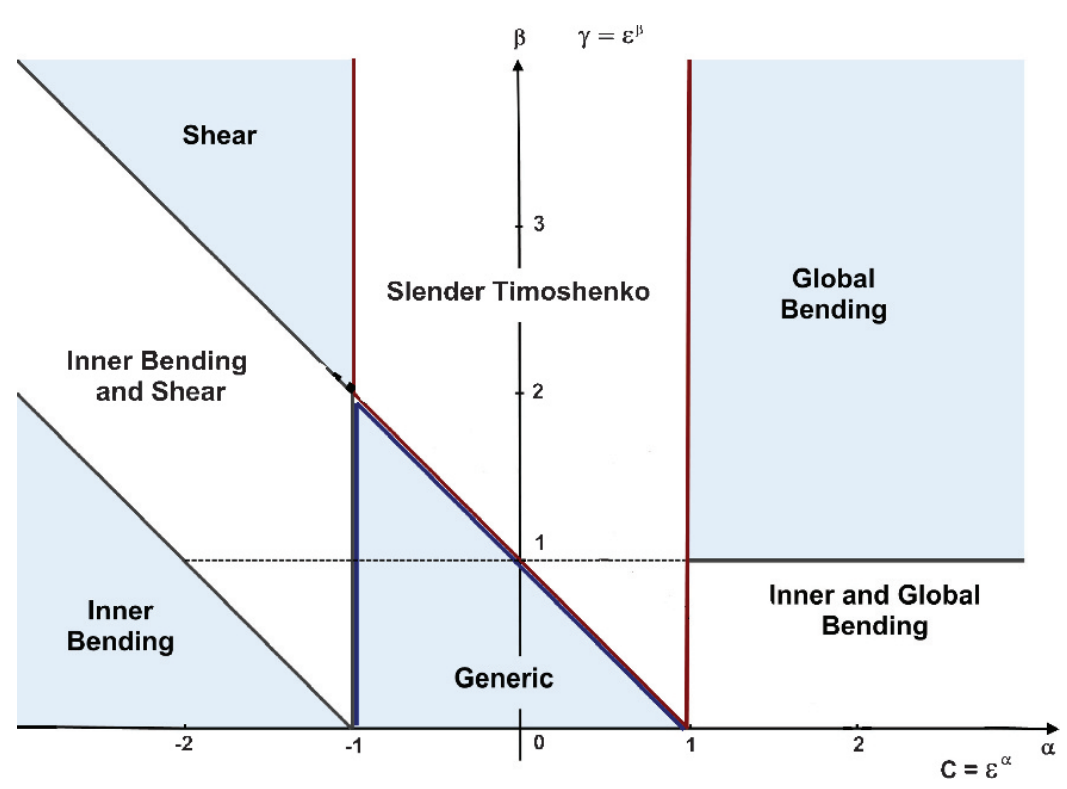

Fig. 3.1.9 Domains of validity of the equivalent beam according to values $\alpha$ and $\beta$ defined by $\mathrm{C}=\varepsilon^{\alpha}$ and $\gamma=\varepsilon^{\beta}$

For instance, when $C=O(1)$ and $\gamma \mathrm{g} O(\varepsilon)$, Equation (3.1.3) degenerates into:

$$
U^{*(4)}-\omega^{* 2} U^{*(2)}+\frac{\omega^{* 2}}{C} U^{*}=0
$$

which corresponds to a slender Timoshenko beam.

Note that the inner bending effect can participate only if a gap in the bracing of the generic storey exists, like a corridor going through the entire building (e.g. building $\mathrm{C}$ in the transverse direction). Consequently, in absence of such a gap (see building $\mathrm{G}$ for instance), regular buildings behave as a slender Timoshenko beam.

\subsubsection{An example: The slender Timoshenko beam}

We focus in this section on the slender Timoshenko beam model, whose equation is:

$$
E I U^{(4)}(x)+\frac{E I}{K} \Lambda \omega^{2} U^{(2)}(x)=\Lambda \omega^{2} U(x)
$$

that will be used to describe the behaviour of the building $\mathrm{G}$ in the following. The feature of such a beam are characterized by the single parameter $C$. The beam degenerates into an usual Euler-Bernoulli beam when $C=0$ and into a pure shear beam 


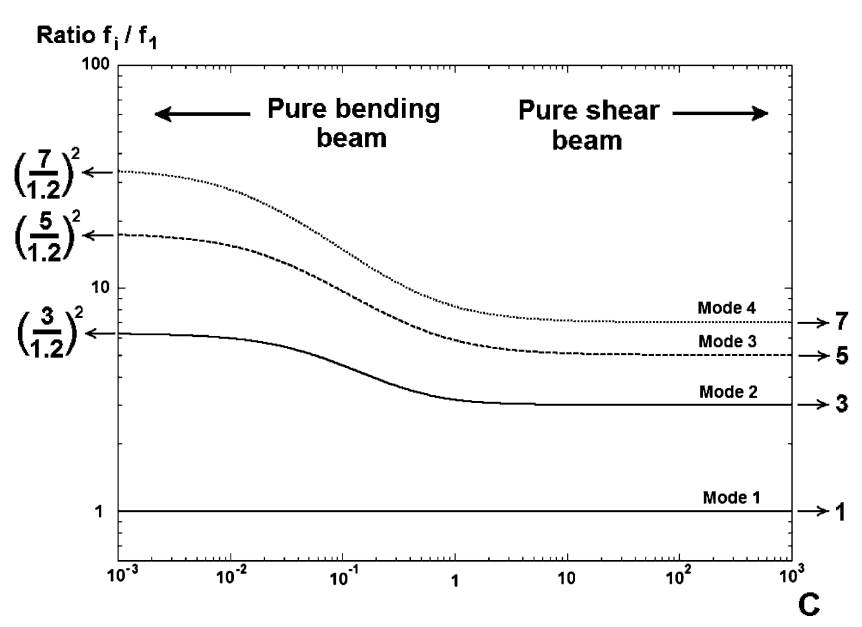

Fig. 3.1.10 Evolution of frequencies ratio $\mathrm{f}_{i} / \mathrm{f}_{1}$ in function of parameter $\mathrm{C}$

when $C=+\infty$. The usual modal analysis applied to this Timoshenko beam clamped at the base and free at the top, gives the $k$ th eigen frequency:

$$
f_{k}=\frac{1}{2 \pi L} \frac{\delta_{1 k}^{2}}{\sqrt{\frac{\Lambda L^{2}}{E I}+\delta_{1 k}^{2} \frac{\Lambda}{K}}} \quad \text { with } \quad \delta_{1 k} \quad \text { closeto } 2 k+1
$$

The distribution of the eigenfrequencies strongly depends on the nature of beam: the sequence is almost homothetic to the odd integer sequence for beam where the shear dominates (say $C>5$ ), whereas, for beams where the bending dominates (say $C<0.05$ ), the sequence is almost homothetic to the square odd integer sequence $(2 k+1)^{2}$. Moreover the ratio between two eigenfrequencies depends on the parameter $C$ only. For instance, as illustrated in Figure 3.1.10, the ratio of the two first frequencies monotonically decreases when $C$ increases. Therefore there is a bi-univoque relationship between this ratio and the beam parameter $C$. It is worth mentioning that this observation provide a very simple way to identify the nature of the beam from the sequence of the measured eigenfrequencies or even from the $f_{2} / f_{1}$ ratio.

\subsubsection{Basic assessment of the beam parameters}

To go further in the identification of the building with a slender Timoshenko beam, we have to specify how the shear $(K)$ and bending $(E I)$ stiffness (in a given main horizontal direction) and lineic density $(\Lambda)$ can be determined. 
The lineic density $\Lambda$ is estimated accurately from the plans, and the density of materials (a mean value of $2.3 \mathrm{t} / \mathrm{m}^{3}$ is adopted for the reinforced concrete). The elastic beam constants are estimated using the following assumptions:

- Perfectly rigid connections are assumed between the structural elements.

- The elastic modulus and Poisson ratio of the material are estimated from usual values ( $\mathrm{E} \approx 20 \mathrm{GPa} v \approx 0.2$ for reinforced concrete).

- The floors are assumed infinitely rigid (this assumption is only partially justified and considered in a first level of analysis).

The storey shear stiffness is derived by imposing a differential horizontal drift to two successive rigid floors. This drift applies to the columns and bearing walls whose extremities are clamped on the floors. The elements stiffness is given by usual static formulae that include bending (dominating for columns and out of plane wall motions) and shear (dominating for in plane wall motions). According to these stiffnesses, a global horizontal force is obtained by summing up the contributions of all the elements. This force divided the shear strain (i.e. the differential drift divided by the height of the storey) defines the storey shear stiffness in the studied direction.

The storey bending stiffness is obtained in a similar way. Imposing to two successive floors a differential rotation around a given horizontal axis lead to a linear distribution of positive and negative vertical tensile strains in columns and bearing walls. According to their normal stiffness, this results in a distribution of traction and compression forces giving a global momentum (the position of rotation axis corresponds to a zero global compressive force). The coefficient relating the momentum to the curvature (i.e. the differential rotation divided by the height $\ell$ of the storey) defines the global bending stiffness in the considered direction.

The Table 3.1.5 gives the numerical results obtained for the building $\mathrm{C}$ (longitudinal direction) and building $\mathrm{G}$ in both longitudinal and transversal directions. Clearly the $C$ value indicates a dominating shear beam behavior for building $\mathrm{C}(C \approx 20)$, and a Timoshenko beam behavior in both directions for building $\mathrm{G}(0.1<C<2)$. The three first frequencies calculated from these estimations show an acceptable accordance with the experimental values (at least for these modes), meaning that this model provides a reasonably good description of the building behavior.

Table 3.1.5 Basic estimations on tested buildings with $\mathrm{E}=20 \mathrm{GPa}$

\begin{tabular}{llll}
\hline Building & \multicolumn{1}{c}{$\mathrm{C}$} & \multicolumn{2}{c}{$\mathrm{G}$} \\
\hline Direction & Longitudinal & Longitudinal & Transversal \\
\hline Lineic mass $(\mathrm{t} / \mathrm{m})$ & 114 & 110 & 110 \\
Shear parameter $\mathrm{K}(\mathrm{MN})$ & 11,895 & 27,830 & 115,600 \\
Bending inertia I $\left(\mathrm{m}^{4}\right)$ & 2,140 & 1,836 & 354 \\
Estimated frequencies $\left(f_{1} ;\right.$ & $3.63-11.5-17.8$ & $2.58-7.91-14.12$ & $2.24-10.54-23.07$ \\
$\left.f_{2} ; f_{3}\right)$ & & & \\
Experimental frequencies & $4.45-14.1-23.5$ & $2.15-7.24-13.97$ & $1.56-6.64-14$ \\
\hline
\end{tabular}




\subsubsection{Experimental derivation of the beam parameters}

To complement the a priori assessments, the beam parameters can also be estimated independently from the experimental sequence of eigenfrequencies.

\section{Building C}

According to the previous result, building $\mathrm{C}$ can be modeled, in its longitudinal direction, by a pure shear beam characterized by its shear stiffness $K=E \cdot S_{S}$, where $S_{s}$ reflects the geometry of the structure. Then, the lineic density and the geometry being known, the identification of the beam parameter reduces to determine the Young's modulus $E$. It is therefore possible to adjust the modulus of the material. In the present case, the fit of the first eigenfrequency of the model with the experimental value $(4.45 \mathrm{~Hz})$ yields the realistic value $E=31 \mathrm{GPa}$. Moreover, with this modulus, the three first model eigenfrequencies are respectively $4.45-13.3-21.8 \mathrm{~Hz}$ very close to the experimental ones $4.45-14.1-23.6 \mathrm{~Hz}$.

\section{Building G}

For building G, Timoshenko beams were found in the direct procedure to explain the dynamic behavior in both directions. Now, as seen above, the ratio of the two first eigenfrequencies $f_{2} f_{1}$ yielding to a unique value of $C$, two experimental values of $C$ - one for each direction - are given from the experimental ratio $f_{2 /} f_{1}$. The experimental $C$ values - respectively 0.51 and 0.134 in the longitudinal and transverse directions - confirm the Timoshenko behaviour - see Figure 3.1.10. Then, using the first frequencies, the stiffness parameters $(E I$ and $K)$ can be determined for each direction. The Table 3.1.6 gives the results obtained by this procedure. Observing that the longitudinal value $(29,288 \mathrm{MN})$ of $K$ is very close to that $(27,830 \mathrm{MN})$ derived by the direct procedure (Table 3.1.5), it can be conclude that, for this direction, the assumption of rigid floors is satisfactory. Then, the fitting with experimental value leads to evaluate the concrete modulus to $21 \mathrm{GPa}$.

Table 3.1.6 Experimental refitting on Building G. The Young's modulus ( $21 \mathrm{GPa}$ ) is found by fitting the first longitudinal frequency

\begin{tabular}{lll}
\hline Direction & Longitudinal & Transversal \\
\hline Experimental frequencies $(\mathrm{Hz})$ & $2.15-7.24-13.97-20.5$ & $1.56-6.64-14$ \\
Experimental ratio $f_{2} / f_{1}$ & 3.37 & 4.26 \\
Experimental C & 0.510 & 0.134 \\
Fitted beam model frequencies $(\mathrm{Hz})$ & $2.15-7.24-13.97-20.1$ & $1.56-6.64-14$ \\
Shear parameter K $(\mathrm{MN})$ & 29,288 & 36,808 \\
Global bending stiffness El $\left(\mathrm{MN} \cdot \mathrm{m}^{2}\right)$ & $1.13 \times 10^{7}$ & $3.74 \times 10^{6}$ \\
\hline
\end{tabular}




\subsubsection{Checking the relevancy of the continuous beam modelling}

The beam parameters in accordance with experimental data being now available, the reliability of the modelling can be checked by complementary comparisons. For this purpose, the mode shapes and eigenfrequencies of higher modes have been calculated and compared to the experimental data.

The eigenfrequencies are well described by the beam models, up to the third frequency for building $\mathrm{C}$ - though only the first was fitted - and up to the fourth for building G, tough only the two first frequencies were fitted (Table 3.1.6).

The Figure 3.1.11 presents the comparison of mode shapes for building G. Despite the mode shapes were not involved in the fitting process, there is a very good agreement between experiments and modelling, even for the modes whose frequencies were not fitted. Note also that the first mode curvature is consistent with the beam model: negative for beam with dominating bending effect (transversal direction); with an inflexion for Timoshenko beam (longitudinal direction).

Let us also mention that the modulus $E$ experimentally determined $(20<E<$ $30 \mathrm{GPa}$ ) are realistic, and argue in favour of the reliability of this approach. Finally, the consistency of the results (also observed for building C) lead to think that even moderately tall buildings can actually be considered as beams, whose parameters can be determined rather simply from basic information and in-situ measurements.

\subsubsection{Seismic thresholds of damage}

The question addressed here is: how these experimental data, consistently described by a beam modelling suited to the structure, could contribute to a seismic

Longitudinal direction

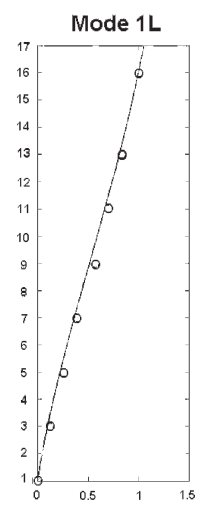

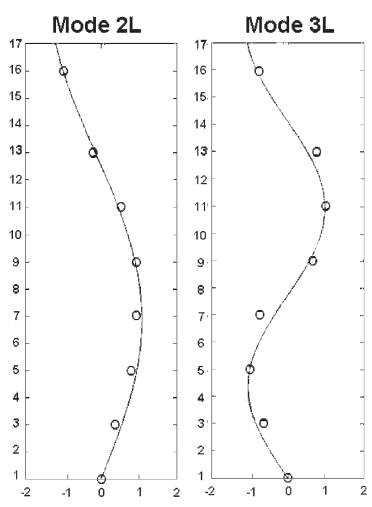

Experimental data

o
Transversal direction

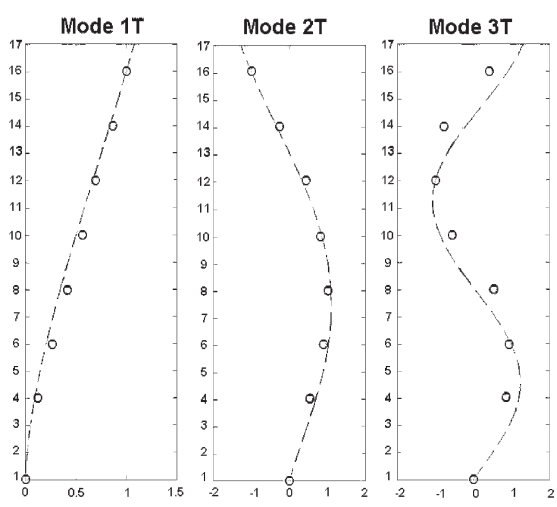

Timoshenko beam

$C_{L}=0.5---C_{T}=0.13$

Fig. 3.1.11 Modelling-experiment comparison of modal shapes for the building G 
vulnerability diagnosis? It should be emphasized that one focus here on reinforced concrete structures (but the same principle can be adapted to other types of structures).

\subsubsection{Principle}

Since a reliable description of the (quasi) elastic building behavior (including all the mechanically active elements) is available, the first idea consists in determining the limit of this elastic domain. More precisely, it is intended to estimate the seismic acceleration level - related to the normalized spectra given by the code - which generates the onset of structural damages. Beneath this level, called Seismic Threshold of Elasticity (STE), the structure remains elastic, i.e. undamaged. In the same spirit, the second idea is to estimate the level corresponding the onset of plastic hinge, called Seismic Threshold of Yielding (STY).

For determining these thresholds, strain criteria for concrete and steel will be adopted. It is worth mentioning that, in addition to simplicity, this choice overcome the lack of information on the amount and position of steel bars. In fact, this deficiency avoid the use of stress criteria that should necessarily include the reinforcements. Note also that strain criteria are consistent with the displacementbased vulnerability assessment methods, Priestley (1997), or the concept of maximum story drift (Gulkan et al., 1996).

\section{Criterion for the onset of structural damages}

As for the onset of structural damage, a criterion of maximum tensile strain of concrete is taken. In fact, whatever the amount of reinforcements, the concrete matrix can not sustain tensile strains greater than $10^{-4}(\mathrm{~m} / \mathrm{m})$ (for usual concretes). Below this limit, the concrete (and thus the reinforced concrete) remains intact; above, the cracking of the concrete begins and weakens the reinforced concrete elements. Note that the maximum tensile strain can be adapted for other material (e.g. parpen).

\section{Criterion for the onset of plastic hinge in reinforced concrete columns}

As for the onset of plastic hinge, a criterion of maximum elastic tensile strain of steel and compression strain of concrete is taken. Indeed, the failure by compression of the concrete matrix and the yielding of usual steel bars begin for tensile strains greater than $10^{-3}(\mathrm{~m} / \mathrm{m})$. Note that up to this strain level, the damage of the concrete in the columns remains limited: typically, the unconfined concrete cover is ejected at the extremities of the columns. This localized reduction of the effective section and inertia acts as a softening of the connections. This effect being limited, its impact is weak on the global stiffness of the structure. For these reasons, one may admit - in first approximation - that after the onset of concrete damages and before the onset 
of plastic hinges, the first modal frequency and shape are almost unaffected (say a decrease of about 10\%), at least for framed structures (remind that for buildings of five storeys and more, if the stiffness of the ground floor is divided by 2 [resp. 5], the frequency is only reduced of $20 \%$ [resp. $40 \%$ ]). This might not apply to walls, whose shear cracks affect the whole element.

\section{Seismic thresholds of damage}

The Seismic Threshold of Elasticity (STE) is deduced from:

- The quasi-elastic behavior identified from ambient vibration tests

- The beam model deduced from experiments suited to the building structure

- The damage criterion of concrete

It is clear that, if the structure was purely elastic, its temporal response to any seismic shaking could be fully determined. Obviously, this response will coincide with that of the real structure until the onset of damage, afterwards 'elastic' and 'damaged' response begin to diverge. Consider now signals respecting the normalized earthquake spectra, whose amplitudes are characterized by the normalized accelerations. In the quasi-elastic domain, the response of the building increases proportionally to the amplitude of the signal, i.e. the normalized acceleration. This will be true until a first damage appears in concrete somewhere in the structure. At this moment, the corresponding normalized acceleration will be called the Seismic Threshold of Elasticity (STE). Note that the localization of the first structural damages can be achieved from the deformed structural shape defined according to its quasi-elastic vibration modes.

The Seismic Threshold of Yielding (STY) is defined in a similar way. However the additional assumption of weak non linear effect before steel yielding must be introduced. The threshold expressed in terms of normalized acceleration is reached when somewhere in the structure the strain in the vertical direction (of the steel bars) reaches the elastic strain limit of steel in tension and concrete in compression.

\section{Calculation of the thresholds using the first mode approximation}

In the frame of these assumptions, the calculation of the thresholds could be performed through common linear dynamic numerical methods, the model being fitted by the experimental data. In order to give a better insight of the method, the calculation are performed using the first mode approximation. This latter consider that the first mode is mainly responsible for the structural deformations. This simplification can be partially justified:

- The distribution of seismic energy is such that for buildings with well separated eigenfrequencies (e.g. 4.45 and $14.1 \mathrm{~Hz}$ for building C), the maximum of energy is concentrated on the first mode.

- The participation factor, then the effective amplitude, is smaller for higher modes. 
It is then possible to straight estimate the amplitudes of the first mode displacements which would lead to the onset (i) of structural damages and (ii) of plastic hinges. Using the normalized elastic response spectra provided by the codes, these modal amplitudes can be converted into the corresponding acceleration levels, i.e. the STE and STY.

\section{Practical interest of the threshold values}

The Seismic Threshold of Elasticity corresponds to a seismic elastic limit, whereas the safety strategy against earthquake is based on ductility. In these conditions, it is important to clarify why the knowledge of the STE could be of interest for the assessment of the vulnerability:

- As the STE value is based on measured data and does not require any supplementary assumptions on the post elastic behavior, the uncertainty is minimized.

- The fact that the STE is associated with normalized elastic response spectra should mean a real benefit for earthquake engineering practitioners. Moreover, site effects could be easily integrated by using specific spectra suited to the site.

- The comparison of the STE value with the level of acceleration required by the seismic code gives an assessment of the ductility that the structure should be able to develop; this can be a useful tool to identify the more critical cases, or to define a strategy of reinforcement.

- For the large number of buildings made of materials of low (slightly reinforced concrete) or very low (masonry) ductility, the STE value can be a close indicator of the acceleration level leading to severe damages (nevertheless the reserves of stability brought by hyperstatism may preserve from collapse).

- Finally, for specific buildings that should be kept in service, the STE value should help to estimate whether the damage level remains acceptable.

Beyond the Seismic Threshold of Elasticity, for framed reinforced concrete buildings, the post-elastic behavior is expected to induce limited damages in the columns up to the STY level. Beyond STY, significant damages can be expected depending on the ductility potential and its effective use during earthquake:

- If the quasi-elastic mode shape clearly shows a level which concentrates the deformation (for instance in presence of a 'transparent' level), the strength will essentially depends on the local ductility at this level, the ductility of other parts of the building remaining almost unemployed.

- If the design ends up in a regular mode shape, the ductility will be activated in the whole building, and after the onset of plastic hinge (STY), the strength can be estimated using a push-over analysis, (Priestley, 1997) (assuming or knowing the amount and disposition of steel reinforcement).

To sum up, if the STE is lower than the acceleration required by the seismic code, it is believed that first damages would be induced by the reference earthquake. The gap between the Thresholds values and the reference acceleration of the seismic 
zone provides an indication of the ductility needed by the building to resist to the reference earthquake. The larger this gap is, the more attention should be paid to the structure.

As an example, the calculation of STE is illustrated in the next section on building $\mathrm{C}$, using the first mode approximation.

\subsubsection{Case study: STE of building $C$ in the longitudinal direction}

\section{Internal strain limits of the structural elements}

As presented in Section 3.1.6.3, the building $\mathrm{C}$ behaves longitudinally as a pure shear beam. Then, at a given floor level $i$, in each structural element $e$, the strain tensor $[\varepsilon]_{i, e}$ (non uniform) results from:

- The strains $\left[\varepsilon^{d}\right]_{i, e}$ given by the dead loads (including the own load and for the carrier elements, the load of higher levels)

- The strains $[\varepsilon]_{e}\left(\Delta u_{i}\right)$ imposed by the inter-storey displacement $\Delta u_{i}$ and composed by the linear functions $\left[\varepsilon^{s}\right]_{e}$ given by the shear and $\left[\varepsilon^{b}\right]_{e}$ by the bending

$$
[\varepsilon]_{i, e}=\left[\varepsilon^{d}\right]_{i, e}+\left[\varepsilon^{s}+\varepsilon^{b}\right]_{e}\left(\Delta u_{i}\right)
$$

The strain tensor $\left[\varepsilon^{d}\right]_{i, e}$ is fully identified assuming a normal and uniform stress distribution in the cross-section (with the values $\mathrm{E}=30 \mathrm{GPa}, v=0.2$ ). The strain tensors under unit inter-storey displacement $\left[\varepsilon^{s}\right]$ and $\left[\varepsilon^{b}\right]$ are classically derived. Then, the diagonalization of $[\varepsilon]_{i, e}$, leads to an analytic expression of the maximum tensile strain parameterized by inter-storey displacement $\Delta \mathrm{u}_{i}$.

For each structural element $e$ of each floor level $i$, one may deduce the relative displacement $\Delta u_{i, e}^{l i m}$ for which the limit tensile strain of $10^{-4}$ is reached. At the floor level $i$, the inter-storey displacement $\Delta u_{i}^{\text {lim }}$ which triggers off the damage is the minimum of the $\Delta u_{i, e}^{l i m}$ values of the whole elements of the storey. Because of the dead load force, these values vary with the floor levels.

For longitudinal vibrations of building $\mathrm{C}$, the critical elements are the full precast panels, on ground floor and the three first levels; the walls of the lifts cage, above.

For calculating the STY, it is sufficient to consider the tensile strain in the vertical direction (instead of the maximal tensile strain) and to replace the limit tensile strain of concrete by the elastic strain limit of steel. This leads to the inter-storey displacement $\Delta v_{i}^{\text {lim }}$ that would onset the yielding of a steel bar on the floor level $i$.

\section{Seismic threshold of elasticity of Building C}

Let's introduce $\left[U_{1}^{*}\right]$ and $\left[\Delta U_{1}^{*}\right]$, the normalized first mode eigenvector $\left(\left|U_{1}^{*}\right|=1\right)$ and the corresponding differential displacement vector, respectively. If $A$ is the amplitude of the first mode, then the displacement and differential displacement are: 


$$
\left[u_{1}\right]=A \cdot\left[U_{1}^{*}\right] \quad \text { and } \quad\left[\Delta u_{1}\right]=A \cdot\left[\Delta U_{1}^{*}\right]
$$

The amplitude $A_{i}$, that would trigger off the structural damages at the floor $i$, reads:

$$
\Delta u_{i}^{l i m}=A_{i} \cdot\left[\Delta U_{1}^{*}\right]_{i}
$$

The minimum of $\left\{A_{i}\right\}$ is the amplitude $A_{\text {lim }}$ triggering off the damage in the building.

It remains now to transform the value of $A_{\text {lim }}$ into an acceleration level. Conveniently, the seismic codes give the normalized elastic response spectra, i.e. the maximum displacement $d^{*}(f)$ of single-degree of freedom oscillators (SDOF) of eigen frequency $f$, submitted to signals conform to the seismic spectra, with a reference acceleration of $a^{*}=1 \mathrm{~m} / \mathrm{s}^{2}$. For a standardized acceleration $S . a^{*}$, according to the modal analysis, the amplitude of the modal response of the structure of first mode frequency $f_{1}$ is:

$$
A(S)=S \cdot p_{1} \cdot d^{*}\left(f_{1}\right)
$$

where $p_{1}=\frac{{ }^{t}\left[U^{*}\right][M][1]}{t\left[U^{*}\right][M]\left[U^{*}\right]}$ is the first modal participation factor $\left(p_{1}=\pi / 4\right.$ for pure shear beam). The STE is reached for a standardized acceleration $S T E \cdot a^{*}$ such that $A(S T E)=A_{\text {lim }}$, i.e.,

$$
S T E=\frac{A_{\text {lim }}}{p_{1} \cdot d^{*}\left(f_{1}\right)}
$$

Therefore, the STE, i.e. the level of ground acceleration corresponding to seismic elastic limit of the building can be derived according to the code recommendations. The STY could be deduced similarly by replacing $\Delta u_{i}^{\text {lim }}$ by $\Delta v_{i}^{\text {lim }}$.
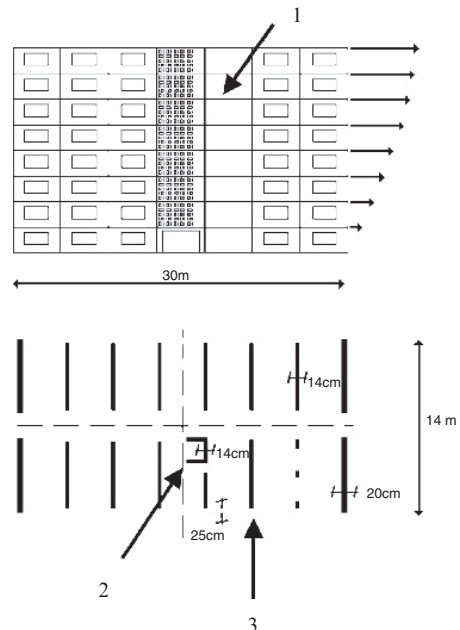

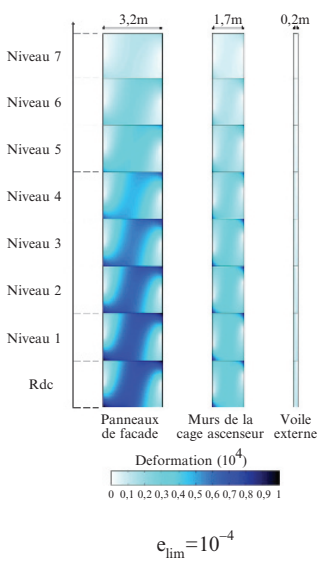

\begin{tabular}{|c|c|c|}
\hline \multirow{2}{*}{ Site } & \multicolumn{2}{|c|}{ Critère d'intégrité $(\mathrm{m} / \mathrm{s}$ ?) } \\
\cline { 2 - 3 } & 8 niveaux & 4 niveaux \\
\hline S0 & 0,45 & 0,92 \\
\hline S1 & 0,45 & $1,07>\mathbf{I a}$ \\
\hline S2 & 0,57 & $1,42>$ Ia \\
\hline S3 & 0,78 & $1,84>\mathbf{I a}, \mathrm{Ib}$ \\
\hline
\end{tabular}

Fig. 3.1.12 Strain limits of the main structural elements of the building C

\begin{tabular}{|c|c|}
\multicolumn{2}{|c}{ Norme PS 92} \\
Zone & $\begin{array}{c}\text { Accélération } \\
\text { réglementaire } \\
(\mathrm{m} / \mathrm{s} ?)\end{array}$ \\
\hline Ia & 1 \\
\hline Ib & 1,5 \\
\hline II & 2,5 \\
\hline III & 3,5 \\
\hline
\end{tabular}

(n)


Considering a damping ratio of 5\%, the STE values of building C in the longitudinal direction are presented in Figure 3.1.12, considering that the structure is settled on different site conditions, from $S_{0}$ (very good soil) to $S_{3}$ (soft soil). To investigate the sensibility of the STE, the same calculations were developed for a fictitious building $C^{\prime}$ identical to $\mathrm{C}$ but with a number of storey reduced to 4 (therefore more rigid with an higher first frequency). It can be seen that, according to the site conditions, the STE values of the building $\mathrm{C}$ range between 0.05 and $0.08 \mathrm{~g}$. This order of magnitude is in agreement with the post-earthquake observations which showed that below $0.1 \mathrm{~g}$, there are very limited structural disorders in common concrete buildings. The STE values of building C', less solicited because of its higher frequency, take higher values $(0.09-0.18 \mathrm{~g})$.

\subsubsection{Conclusions}

This study shows the interest of the ambient noise vibration in the seismic diagnosis of existing structures. The experiments prove the robustness and the reliability of information collected through ambient vibrations which enable to identify the leading and negligible phenomena. Even if the data are limited to the quasielastic domain, their knowledge is of very first importance: the quasi-elastic behavior is known to play an essential part specially for the dynamic amplification near eigenfrequencies, this phenomenon being one of the main reason of the structural damages.

Keeping in mind the necessity of draft analysis for number of buildings, simple approaches have been favored, based on few elementary though physically based assumptions, that give descriptions sufficiently realistic for engineering purposes. On this point, the interest of identifying experimentally several eigenfrequencies, instead of the only fundamental frequency, is underlined.

The concept of equivalent beam yields a drastic simplification in the modelling of dynamic behaviour of regular buildings: the complete dynamic calculation can be achieved in two much more simple independent steps; first the calculation of the beam parameters determined on a single storey in statics; second, the analytic calculation of unidirectional generalized beam in dynamic regime.

In the same spirit, the concept of Seismic Thresholds of damage presents the practical advantages to be based on real data, to minimize the introduction of uncertain assumptions on the non linear post-elastic behavior (at the three scales of the material, the structural elements and the structure) and to provide an acceleration level that can be easily compared with the reference acceleration given by the codes. By comparing reference acceleration and threshold values, the extend of the ductility needed by the structure can be evaluated. The confrontation with the usual ductility of the material could provide a good criterion to identify the most vulnerable structures. Although the results could be regarded as coherent, further improvements should be done, for instance considering the simultaneous presence of several 
modes (in two directions), and extending the applications to buildings made of different materials.

It should be also emphasized that, if the limits of service must be evaluated or a retrofitting is needed, experimental data allow a good fitting of the numerical modelling. Indeed whatever the complexity of the linear and non-linear numerical method, the results depend on the chosen assumptions. The knowledge of the quasi-elastic behavior help to reduce the uncertainty of the modelling and as well to define an adequate reinforcement owing to a better understanding of the structure.

As a conclusion, the association of experimental and simple models can be a good complement of the existing methods.

Acknowledgements This research was supported by the French Ministry of Environment and the French Association of Earthquake Engineering (AFPS).

\section{References}

Argoul P, Hans S, Conti F, Boutin C, Time-frequency analysis of free oscillations of mechanical structures. Application to the identification of the mechanical behaviour of buildings under shocks, Proceedings of the System Identification and Structural Health Monitoring - COST F3 Conference, Madrid, Spain, 2000, pp. 283-292.

Benedetti D, Benzoni G, Parisi MA, Seismic vulnerability and risk evaluation for old urban nuclei, Earthquake Engineering and Structural Dynamic, 1988, 16, 183-201.

Boutin C, Hans S, Using buildings to be demolished for vulnerability assessment, Acts of the Eleventh European Conference on Earthquake Engineering, Paris, 1998.

Boutin C, Hans S, Dynamics of periodic framed structures - Continuum modelling by homogenisation, Computer and Geotechnics, Special Number: Homogenisation in Geomechanics, 2003, 30(4), 303-320.

Boutin C, Hans S, Ibraim E, Roussillon P, In situ experiments and seismic analysis of existing buildings - II seismic integrity threshold, Earthquake Engineering and Structural Dynamics, 2005, 34, 1531-1546.

Dunand F, Pertinence du bruit de fond sismique pour la caracterisation dynamique et l'aide au diagnostic sismique des structures de Gnie Civil, Ph.D. thesis, Universite Joseph Fourier I, Grenoble, 2005.

Ellis BR, Full-scale measurements of the dynamic characteristics of buildings in the UK, Journal of Wind Engineering and Industrial Aerodynamics, 1996, 59, 365-382.

Englekirk RE, Matthiesen RB, Forced vibration of an eight-story reinforced concrete building, Bulletin of the Seismological Society of America, June 1967, 57(3), 421-436.

Farsi MN, Identification des structures de Genie Civil a partir de leur reponse vibratoire. Vulnerabilite du bati existant. These Universite Joseph Fournier, Grenoble, December 1996.

Gulkan P, Sozen MA, Demir S, Ersoy U, An alternative evaluation for determining seismic vulnerability of building structures, Acts of the Eleventh World Conference on Earthquake Engineering, Acapalco, Mexico, 1996.

Hans S, Auscultation des batiments existants, Ph.D. thesis, ENTPE- INSA, Lyon, 2002.

Hans S, Boutin C, Dynamics of discrete framed structures - Unified homogenized description, submitted, 2008.

Hans S, Boutin C, Ibraim E, Roussillon P, In situ experiments and seismic analysis of existing buildings - I Experimental investigations, Earthquake Engineering and Structural Dynamics, 2005, 34, 1513-1529. 
Hudson DE, Dynamic tests of full-scale structures, Earthquake Engineering, Prentice-Hall, 1970, 127-149.

Ivanovic SS, Trifunac MD, Todorovska MI, Ambient vibration tests of structures - A review, Bulletin of Indian Society of Earthquake Technology: Special Issue on experimental methods, December 2000, 1-49.

Jennings PC, Kuroiwa JH, Vibration and soil-structure interaction tests of a nine-story reinforced concrete building, Bulletin of the Seismological Society of America, June 1968, 58(3), 891-916.

Paquet J, Etude experimentale du comportement dynamique des structures, Annales de ITBTP, December 1976, n200, 129-151.

Petrovski J, Jurukovski D, Paskalov T, Dynamic properties of fourteen-story reinforced concrete building from full-scale forced vibration study and formulation of mathematical model, Proceeding of Fifth World Conference on Earthquake Engineering, Rome, Italy, 1973.

Priestley MJN, Displacement-based seismic assessment of reinforced concrete buildings, Journal of Earthquake Engineering, 1997, 1(1), 157-192.

Spence RJS, Coburn AW, Pomonis A, Correlation of ground motion with building damage: The definition of a new damage-based seismic intensity scale, Acts of the Tenth World Conference on Earthquake Engineering, Madrid, Spain, 1992.

Stephen NG, On the vibration of one-dimensional periodic structures, Journal of Sound and Vibration, 1999, 227(5), 1133-1142.

Stubbs IR, MacLamore VR, The ambient vibration survey, Proceedings of Fifth World Conference on Earthquake Engineering, Rome, Italy, 1973.

Trifunac MD, Comparisons between ambient and forced vibrations experiments, Earthquake Engineering and Structural Dynamics, 1972, 1, 133-150. 